\title{
GREENER TEXTILES IN HOSPITALS
}

Guide to green procurement in the healthcare sector

$\mathbb{1}$ Nordic Council of Ministers 


\section{Greener textiles in hospitals}

Guide to green procurement in the healthcare sector

David Watson, PlanMiljø

Rikke Fisher-Bogason; PlanMiljø

ISBN 978-92-893-4882-9 (PRINT)

ISBN 978-92-893-4883-6 (PDF)

http://dx.doi.org/10.6027/ANP2017-717

ANP 2017:717

(c) Nordic Council of Ministers 2017

Layout: Gitte Wejnold

Coverphoto: Pexels.com

Photos: Scanpix.dk

This publication has been published with financial support by the Nordic Council of Ministers. However, the contents of this publication do not necessarily reflect the views, policies or recommendations of the Nordic Council of Ministers.

\section{www.norden.org/nordpub}

\section{Nordic co-operation}

Nordic co-operation is one of the world's most extensive forms of regional collaboration, involving Denmark, Finland, Iceland, Norway, Sweden, the Faroe Islands, Greenland, and Åland.

Nordic co-operation has firm traditions in politics, the economy, and culture. It plays an important role in European and international collaboration, and aims at creating a strong Nordic community in a strong Europe.

Nordic co-operation seeks to safeguard Nordic and regional interests and princi-ples in the global community. Shared Nordic values help the region solidify its position as one of the world's most innovative and competitive. 


\section{GREENER TEXTILES IN HOSPITALS}

Guide to green procurement in the healthcare sector 


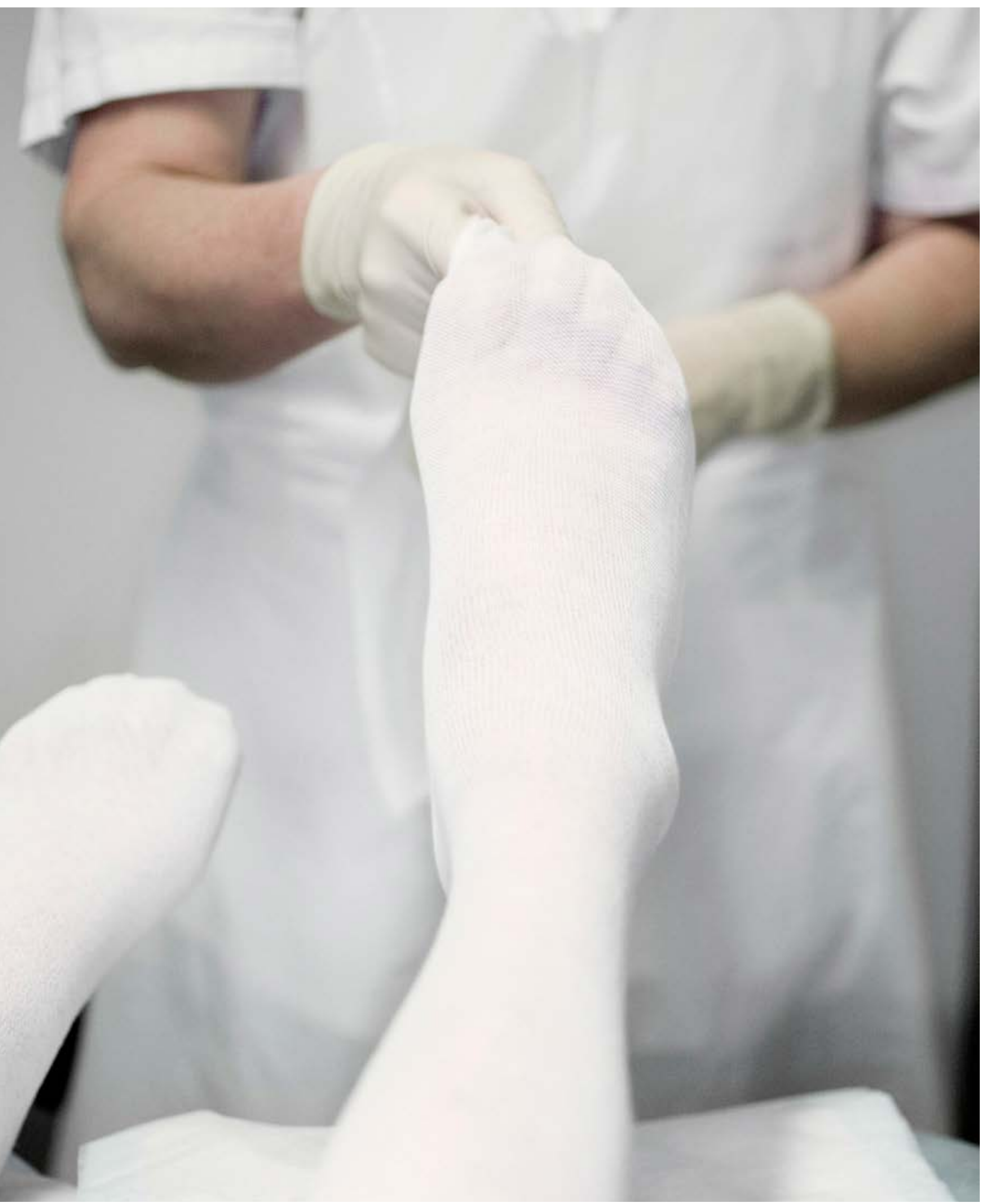




\section{CONTENTS}

6 How to Use this Guide

8 Section 1

The Main Aspects to Keep in Mind

10 Section 2

The Procurement Process, Market Dialogue and Innovation

15 Section 3

Links to Helpful Documents and Resources

22 Section 4

A Quick Overview of Ecolabels

24 Section 5

Choosing your Fibre

28 Section 6

Single Use versus Reusable Textiles

30 Section 7

Using Total Costs of Ownership

33 Section 8

About the Guide and the Network Behind 


\section{How to Use this Guide}

This guide is aimed at procurers in the hospital sector, who are planning to tender for textile products and textile services. The guide will help setting reasonable and feasible environmental criteria and will provide background information for the main aspects to consider, when you are aiming at reducing the environmental impacts of the use of textiles.

Guidance documents can be of great help in assisting and inspiring procurers to realise the potential for environmental and social improvements via public purchases. In this guide, you can learn about the environmental consequences of textile purchases, about available ecolabels and ready-to-use criteria, and which aspects of the textile lifecycle are important to address. It is, however, important that each tendering process is put in the context of the specific organisation and product, and that the procurer considers all organisational and user-related effects of the choices that are made when criteria are set.

Hygiene considerations will always have top priority in decisions related to textiles in the health sector. User comfort should also not be compromised. It is possible to respect these two issues while also reducing environmental impacts. 


\section{A COMPLEX LANDSCAPE OF PROCUREMENT}

There are many different models for procurement of textiles for the health sector in Nordic countries. These can differ in how procurement is organised and what is procured.

- How is procurement organised? - This is complex and varies from country to country and in some cases from region to region. In Denmark, the regions set up a framework for procurement that individual hospitals use to make day-to-day orders. In Norway a central procurement organisation establishes procurement frameworks which individual hospital trusts can decide to make use of or not in which case they organise their own procurement. The structure is ad hoc in Sweden with regions/landsting collaborating in some cases to make framework procurement agreements, but with individual hospitals making smaller orders. In general, framework agreements reduce bureaucracy and resources needed in developing tenders and can help ensure lower prices due to volume.

- What is being procured? - A typical framework will include many tens if not hundreds of textile products from bed linen to patient clothing to staff uniforms and operation room textiles. Alternatively or in addition, regions and hospital trusts may procure textile services or laundry services. Laundry services in particular are often procured by individual hospitals or groups of hospitals which are associated with a laundry, rather than at regional or state level. Laundries can be privately owned, owned by the hospital trust but with an autonomous budget, or publicly owned by a partnership of hospitals and local government. 


\title{
Section 1
}

\section{The Main Aspects to Keep in Mind}

\author{
The consumption of textiles is responsible for 4-6\% of total environmental impacts \\ caused by European consumption.' These impacts are caused both during the \\ production of textiles and their care while in use. For multi-use healthcare textiles, \\ the weight is more towards the use phase, while for single use the impacts will be \\ weighted towards the production phase.
}

This guide focuses on green procurement i.e. how healthcare procurers can reduce the environmental impacts of their purchases. However, procurers may also be interested in pursuing sustainable procurement, which also includes ethical aspects associated with the supply of products. The box on page 18 provides some resources to assist in developing ethical criteria.

To reduce environmental impacts it's a good idea to focus on both areas: choice of textiles you purchase/ lease and how they are laundered (though you may not have influence on the latter). And it's also important to be aware of the links between these issues. Different fibre types may require different treatments.

You can consider both these issues independently of whether you purchase and own the textiles and purchase laundry services; or procure full textile services including a leasing model.

Production-based impacts: A lot of production impacts are caused by use of chemicals and energy in manufacturing. Moreover, residuals of some of the many hazardous chemicals used during production can remain in textile products and can pose a health threat to sensitive users.

These issues are tackled well by various ecolabels, especially the Nordic Swan and the EU Ecolabel (also known as the EU Flower) (see Section 4, page 22) and by the EU GPP criteria for textiles. They are also considered in various national guides for GPP (see Section 3, page 15).

Choice of fibre type is also key: cotton production has high impacts resulting especially from the high use of pesticides, land and water. Choosing organic reduces some of these impacts, but so can switching to other fibres like polyester. There is more on this in Section 5 , pages 24-25.

One critical, but often ignored, way to reduce all production impacts is to extend the use life as far as possible. This will also save money (see Section 7, page 30-31).

As a procurer you can assist by:

1) choosing a durable fibre (see Section 5 , pages 24-25),

2) choosing colours which best tolerate laundering and use by patients and staff

3) setting criteria for laundry services which reduce stress on the textiles. Some ecolabels (see Section 4) include durability criteria as do European (EN) and national standards for textiles ${ }^{2}$ but these are very basic. It is better to gain documentation from suppliers on how many uses/laundry cycles textiles can withstand.

\footnotetext{
1 EEA (2014) Environmental Indicator Report 2014 http://www.eea.europa.eu/publications/environmental-indicator-report-2014

${ }^{2}$ See for example international and Norwegian standards catalogued by Norwegian Standard https://www.standard.no/no/Nettbutikk/produktkatalogen/?ProdCat=11360430
} 


\section{HOSPITAL LOGOS AND AVOIDING UNNECESSARY WASTE}

There are two situations that can lead to disposal of large amounts of otherwise well-

functioning healthcare textiles:

1) a change in the service company from whom you are leasing textiles, and

2) a rebranding/change in the logo of your hospital, district or region.

There are several alternative ways to avoid this significant waste of resources:

1. Write into the contract with a textile service company that textiles may be purchased back by the hospital at the end of the contract period.

2. Choose to have neutral markings on your textiles that can be interchanged between healthcare districts, hospitals etc.

3. Ask your supplier whether textiles can be marked with removable logos.

Use phase impacts: Hygiene is of course the number one priority in laundering of textiles. However, there are ways of reducing impacts of laundering without compromising hygiene. These include greater water and energy efficiency, use of greener detergents and eco-efficient logistics. In some countries (e.g. Denmark and Norway) hospital laundry hygiene guidelines allow reduced washing temperatures provided that detergents are used that have the same sterilising effect (see pages 16-17).

The Nordic Swan label for textile services gives a comprehensive overview of potential improvements. Note though that a laundry service that has a Nordic Swan certificate may have only addressed the most important environmental improvements (see Section 4 , page 22 for more info here).
Finally, though not included in the Nordic Swan label, fibre choice can affect laundering impacts (see Section 5, page 24).

End-of-life choices are also often an issue in environmental decisions. Ensuring that a textile service provider recycles their textiles at end-of-life can add some benefits, but this is not as important for the overall environmental impact as extending the use phase.

An overview of environmental impacts can be found in the Swedish National Agency for Public Procurement's background document for textiles and the agency's background document for textile services and in the EU Joint Research Centre's LCA report. 


\section{The Procurement Process, Market Dialogue and Innovation}

A procurement process can be complex and involves numerous steps and strategic

decisions. If environmental criteria are to be included, it should be decided in

the preparatory phase in order to ensure that the right questions are asked and

decisions are made at the right time.

A first decision to be considered is whether to procure products or procure functions. When the product group is textiles, it means that it will be relevant to consider whether to buy textiles or buy access to textiles - meaning leasing.

Leasing of textiles can have a potential positive effect on environmental impacts. This is due to the fact that ownership of the product is kept with the supplier, who will have an economic interest in ensuring a long product life. The longer a product is kept in use, the lower the environmental impact and use of scarce resources.

Regardless of whether it is decided to buy or to lease textiles and textile services, it is important to consult the market in an initial market dialogue. It is through the market dialogue you can gain knowledge of the products available, of their environmental properties, and of other relevant quality-related aspects (see example on page 11).

Market Dialogue is a dialogue between the client and potential suppliers carried out prior to a formal tendering process in order to ensure that the tender is realistic, and reflects what is available on the market, but is also ambitious.
There are many ways to carry out this dialogue, but the important thing to remember is that it is permitted up until the point in time where the tender is published. After publication, dialogue with potential suppliers is restricted.

What should you ask in a market dialogue? Many aspects will be relevant to address, but in the environmental perspective, the following themes should be discussed:

- Availability of ecolabelled products.

- Availability of organic cotton-based products.

- Use of alternative fibres.

- Textile fibre origin.

- Recycled content.

- Chemical, energy and water management in production.

- Properties related to washing and maintenance.

- Durability properties including reparability.

- Removable logos.

- Colour choice and environmental consequences.

- End-of-life potential (can the textiles be recycled?).

More inspiration for themes to discuss with the market in order to clarify, which environmental criteria can be used, can be found in the EU Commission background note for the GPP criteria on textiles. 


\section{NORWEGIAN SYKEHUSINNKJØP. \\ LETS THE MARKET ASSIST IN SETTING REALISTIC CRITERIA}

In 2014, Sykehusinnkjøp HF (formerly HINAS) procured textiles for the healthcare sector and used a market dialogue process to set suitable environmental requirements. Suppliers were encouraged to comment on a draft criteria set via individual dialogue meetings. The suppliers were invited to these meetings via an online database for public procurement.

The effects of the market dialogue were that there was a shift in procurement demands from $100 \%$ cotton to a more durable blend of polyester/cotton. Suppliers advised that procurers should ask for Oeko-tex 100 labelled textiles, which, though less stringent, could be met in 2014 by far more suppliers than ecolabels such as the Nordic Swan or EU Ecolabel.

Sykehusinnkjøp HF gives the following advice for market dialogue in green textile procurement:

1. Embrace the opportunity of having the market comment in your criteria and help ensure that they are realistic - and also not unambitious.

2. Consider having individual consultations in order to ensure that the suppliers can speak freely and not be inhibited by having the competitors listen in.

3. Remember to let the suppliers challenge your procurement habits - including your choice of fibre and choice of business model.

Contact Evy Pleym at evy.pleym@sykehusinnkjop.no for more info. 
The Swedish Procurement Agency (Upphandlingsmyndigheten) offers assistance to state organisations in engaging in market dialogue. The assistance includes meetings and a workshop with the agency. See here. The agency is also moving forward with a program to develop online resources to assist in market dialogue. The online resource bank does not yet include resources for healthcare textiles.

Due to the rapid development of new technologies/ approaches in the production of textiles it is always important to engage in market dialogue; environmental improvements may be possible of which hospital procurers aren't aware. There are many innovations in production processes and product design on the horizon that can give strong environmental and hygiene benefits (see page 13).

It should be noted that innovative technologies can sometimes run the risk of introducing new environmental problems and should be screened for these before engaging in them.

Procurers can also ensure that latest innovations are used though signing a development contract with suppliers: a longer-term contract with a supplier that allows the supplier to make use of new technologies as they emerge to reduce environmental impacts further. Development contracts can potentially be built around functional criteria (see box below).

\section{USING FUNCTIONAL CRITERIA IN TENDER DOCUMENTS}

In order to allow for development of new products with lower environmental impacts, a procurement contract can be based around functional requirements rather than specifying a given product.

This is most used in for example in procuring energy or lighting services but can also be used for healthcare textiles. For example, a contract could require delivery of clean nurse uniforms sufficient to cover a given number of full-time nursing staff and which meet minimum hygiene, strength, and comfort standards, but without demanding a particular fibre type. Fibres can then be selected by the service provider that meet these standards but with greatest durability to reduce their costs and reduce environmental impacts.

The Swedish Procurement Agency has produced a guide to setting functional criteria that can be accessed here. 


\section{EXAMPLES OF PROMISING INNOVATIONS}

\section{Dry dyeing}

A number of innovative companies have developed dry dyeing processes.

One example uses $\mathrm{CO}_{2}$ instead of water and with no added chemical process chemicals to dissolve dyes. Moreover, the $\mathrm{CO}_{2}$ can be recovered and reused. Dry dyeing avoids wastewater effluents which can cause high environmental impacts in production companies and also avoids the need for drying of textiles between processes thus saving energy.

\section{Biomimicry}

Biomimicry is the application of nature's designs to man-made products. Research in this area has already led to the development of textiles that mimic the stain resistant properties found in lotus leaves. Other natural treatments have focused on mimicking the antimicrobial properties of crab and lobster shells. Textile applications of these technologies are already gaining strength and can give textiles that can be washed at lower temperatures while maintaining high levels of hygiene.

\section{Nanomaterials}

Integration of nano-materials into textile substrates can increase durability of textiles and thus reduce resource consumption and costs. Nano-materials can induce stain repellence, wrinkle-freeness, static elimination, and electrical conductivity to fibres without compromising comfort and flexibility. 


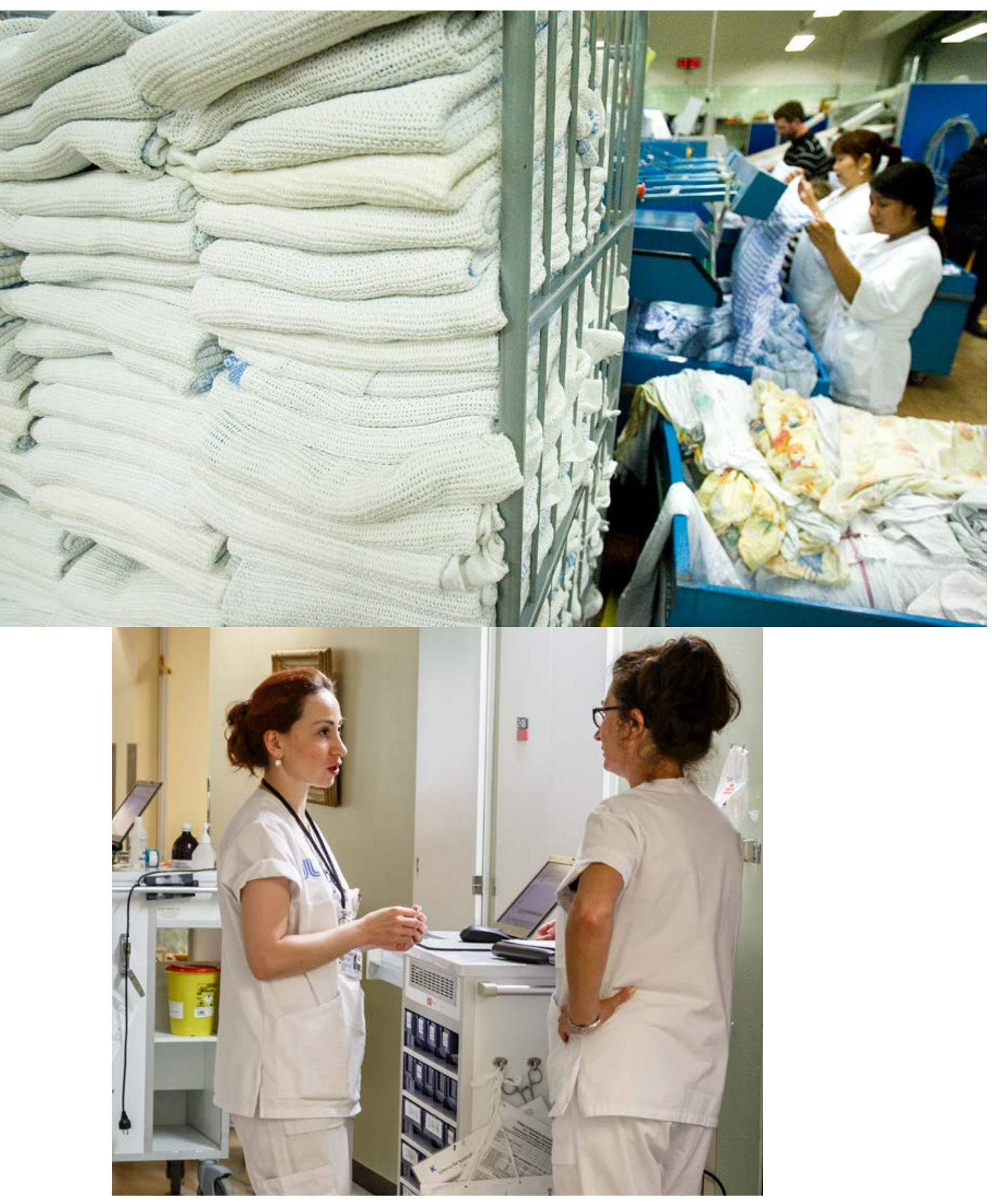




\title{
Links to Helpful Documents and Resources
}

\author{
There are a number of existing guidance documents that can assist procurers in \\ giving consideration to sustainability when procuring textiles and textile services. \\ None of these are specific to textiles for the health sector.
}

EU: The EU developed optional green procurement criteria for textiles in 2012 with the following overall logic:

Key Environmental Impacts

- Air pollution, ozone formation (smog), bioaccumulation or food chain exposure and hazardous effects on aquatic organisms or the increased growth of undesirable aquatic organisms which can degrade water quality, due to the inappropriate use of certain pesticides and fertilisers in the production of fibres, and substances used during the processing of fibres and final textile products

- Negative impact on the occupational health of users due to residues of certain substances harmful to human health

- Avoidance of early failure and consequent waste of textiles by promoting colour -fast fabrics that do not shrink during use
GPP Approach

- Purchase organically produced textiles

- Purchase used textiles which can be reused for their original purpose or purchase textiles that contain recycled fibres

- Purchase textiles with a reduced use of environmentally harmful substances in production

- Purchase textiles with lower residues of substances harmful to human health

- Purchase textiles which meet the minimum requirements for colour fastness and dimensional stability
The criteria include core (minimum) and

comprehensive (more ambitious) criteria for

- residual pesticides in natural fibre products

- residual chemicals and substances potentially used in manufacturing processes

- restrictions in use of particular dyes

- durability characteristics such as shape and colour fastness.

The criteria also include proposals for awarding points for organic production in the supply of natural fibres and share of recycled fibres in a product.

In the GPP criteria most restrictions on hazardous chemicals apply to the presence of residuals in the final product and not to use during production. The exception here is some dyes that the GPP criteria specifically prohibit from production.
Nevertheless, restrictions on residuals of hazardous chemicals in the final product will likely also lead to reduction in their use in production. Moreover, awarding of points for including products of organic cotton and other organic natural fibres will reduce the use of pesticides.

The GPP criteria are in general less strict less than commonly used ecolabels like the Nordic Swan and EU Ecolabel (see Section 4, page 22). The GPP criteria are currently under review and a revised set is expected during early 2017.

National: National procurement agencies in some Nordic countries use the EU criteria directly as guidance for procurers of textiles: e.g. Denmark, Norway, Finland. 


\section{NATIONAL STANDARDS FOR HYGIENE IN HEALTHCARE LAUNDRIES}

When establishing green procurement criteria for laundry services, procurers will also need to respect national guidelines on minimum hygiene standards for these services.

The EU standard EN 14065 describes a risk management approach to continuously assuring the microbiological quality of laundry-processed textiles, and this has been translated in to equivalent national standards. The EN 14065 standard has recently been updated. Links to the EU standard and the equivalent national standards can be found by clicking here:

EU standards; Danish version; Swedish version; Finnish version: Norwegian version

The EN 14065 standard concerns target thresholds and control checks and monitoring systems for bio-contamination at various stages of laundry cycles rather than defining laundry methods to avoid bio-contamination.

However, at least three Nordic countries have standards or guidelines that do define laundry and laundry service methods to be followed to avoid biocontamination:

- Danish standard on handling of multi-use textiles for the health sector.

- Swedish Handbook for Textiles in Healthcare.

- Norwegian standard on Infection control for laundries processing healthcare textiles. 
These differ with respect to washing temperature requirements under thermal disinfection; the Norwegian standard requires $85 \mathrm{deg}$. $C$ for 10 minutes, the Danish standard min. 80 deg. $C$ for 10 minutes and the Swedish handbook advises min. 70 deg. $C$ for 10 minutes.

Both the Norwegian and Danish standards allow for lower washing temperatures provided detergents are used which have the same sterilising effect. The equivalence needs to be regularly monitored. According to a leading laundry services company, ecolabelled detergents exist which can meet these alternative requirements. This may give net environmental benefits compared to sterilising with high temperatures.

The Swedish handbook is guidance rather than a required standard. A scientific study at Uppsala Hospital found that reducing temperatures to $60 \mathrm{deg} C \operatorname{did}$ not increase the risks of bio-contamination provided that it was followed by tumbledrying at a higher temperature of over $110 \mathrm{deg} C$. This nevertheless reduces energy use over the full laundry cycle (Tano and Melhus, 2014)*.

*Tano, E, and Melhus, A. (2014) Level of decontamination after washing textiles at $60^{\circ} \mathrm{C}$ or $70^{\circ} \mathrm{C}$ followed by tumble drying. Infect Ecol Epidemiol. 2014 Nov 11;4:24314. 


\section{CSR AND TEXTILE PROCUREMENT}

Corporate Social Responsibility (CSR) refers to business practices involving initiatives that benefits society. This includes, besides the environmental efforts addressed in this guideline, ethical labour practices, anti-corruption and human rights. These aspects are relevant when procuring healthcare textiles and in some Nordic countries have been in focus for many years.

In Sweden, for example, all regions have a joint code of conduct that suppliers need to sign and answer compliance questions. The code of conduct is based on the United Nations Universal Declaration of Human Rights, the Eight Fundamental Conventions of the International Labour Organisation, The United Nations Convention on the Rights of the Child, the United Nations Convention against Corruption and relevant labour and environmental legislation in the production country. The code of conduct can be found here.

The Swedish regions also have a joint web portal with guidelines and information on CSR, where textiles are regarded as one of nine risk areas in healthcare procurement. Appointed regions are responsible for compliance and audits in each specific product group and textile production have, for example, during the last years been audited in India and Pakistan. The risk assessment can be found here.

The Danish procurement agency includes additional ethical and environmental principles in part comprising Global Compact principles.

The Norwegian agency also provides ethical considerations. Here they promote initiatives aimed at tackling bad working conditions in textile manufacturing: Better Cotton Initiative, Clean Clothes Campaign, ACCORD and IPEC. Of these, the most practicable for use by procurers are the Better Cotton Initiative and ACCORD since it can be seen which brands/manufacturers are involved in the initiatives. There is no guarantee, though, that clothes manufactured for these members (as yet) live up to the principles and goals of the initiatives.

The EU Ecolabel, the Nordic Swan and Bra Miljöval include criteria that encompass labour rights at the textile manufacturing place, (see Section 4, page 22).

Other useful links:

- World Wide Responsible Apparel

- CSR compass 
The Swedish National Agency for Public Procurement has a web resource which includes both guidelines and a comprehensive background document which describes environmental impacts caused by the consumption of textiles, regulations relevant to use of chemicals in textile production and finally lists hazardous chemicals and substances that should be restricted by tender criteria. This list of chemicals goes significantly beyond those included in the non-binding EU GPP criteria, and approaches the chemical-related criteria in the EU Ecolabel and Nordic Swan labels for textiles.

Finally, unlike the other agencies, the Swedish National Agency for Public Procurement also provides a background document and guidance for procuring laundering services. These cover a range of issues around the use and management of chemicals and detergents in washing processes and energy and water consumption and emissions to air from laundry services.
EU and national proposed GPP criteria can all be more than adequately met by textiles that are certified under the Nordic Swan, the EU Ecolabel and Bra Miljöval. The Swedish criteria for laundry services can similarly be met by textile services certified with a Nordic Swan label (see section 4, pages 22-24).

Although not a focus area for this guide the box belowe also provides resources for including ethical criteria in belowe procurement processes.

In the end procurers must choose criteria that fit their needs and environmental (and ethical) ambitions.

Pages 20-21 present a selection of basis criteria used by Sykehusinnkjøp HF, the central procurer in Norway, in a recent tender process for uniforms. The tender also includes further criteria related to end of life of textiles containing hazardous chemicals and criteria related to packaging of products. The criteria are less comprehensive than the EU's set of GPP criteria.

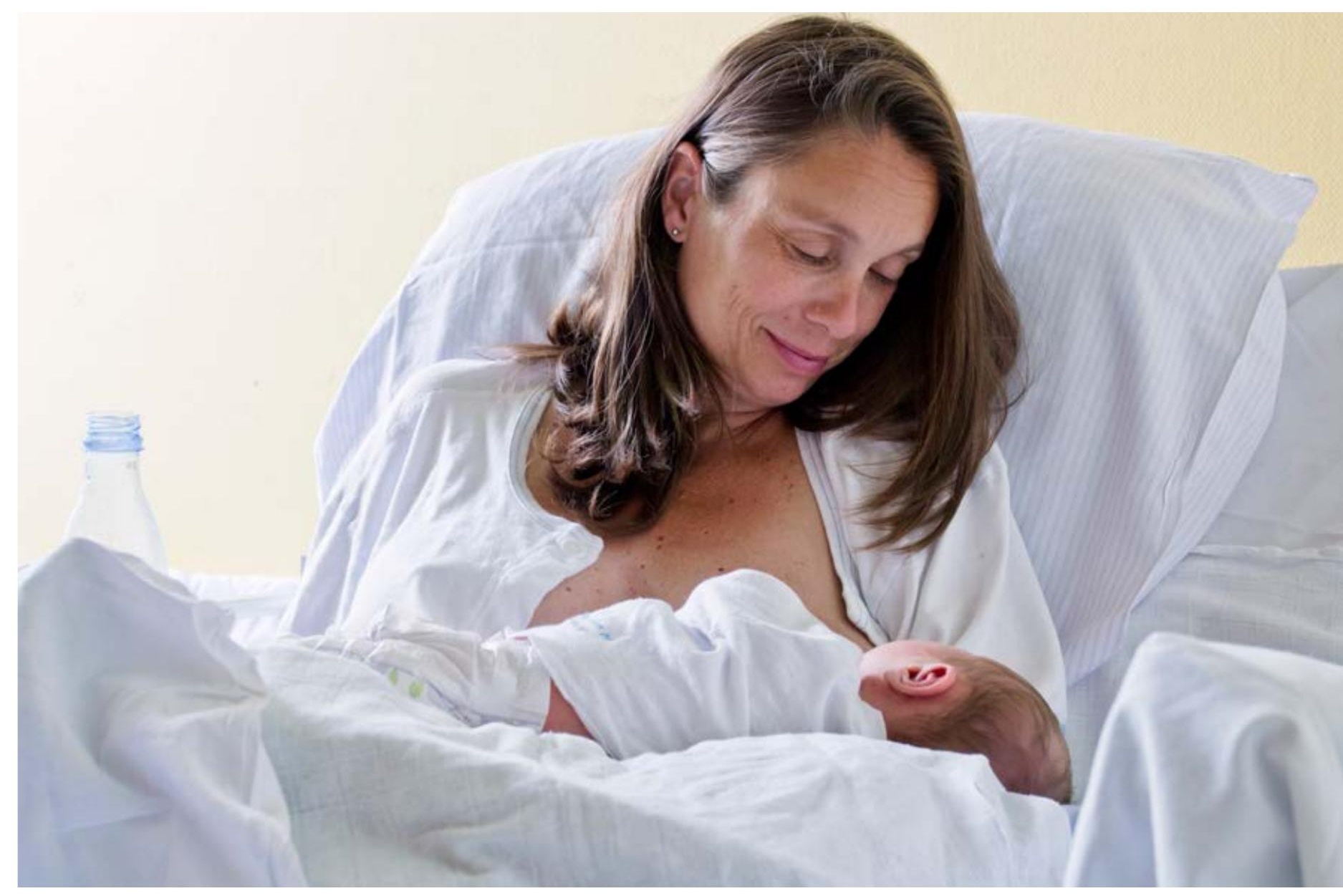




\section{Example of criteria used in a tender for staff uniforms}

(for more info contact Evy Pleym at evy.pleym@sykehusinnkjop.no)

\section{MINIMUM CRITERIA FOR CHEMICALS}

\section{Compliance with legal requirements}

The offered products must comply with requirements contained in the regulations on the restriction of use of hazardous chemicals and other products (Product Regulations (FOR-2004-06-01-922). The offered products must be in accordance with requirements contained in the $\mathrm{REACH}$ chemical legislation.

\section{General requirements}

The products must not contain substances on the EU's candidate list or the Norwegian priority list. This also applies to the use of auxiliary chemicals and detergents.

\section{Use of Pesticides}

Products that are made of cotton or other natural cellulose fibres, the end product should not contain more than $0.05 \mathrm{ppm}$ of each of the following substances and the total content should not exceed 0.75 ppm:

- 2,4,5-T, aldrin, captafol, Chlordane, Klordimeform, DDT, dieldrin, Dinoseb with salts, endrin, heptachlor, Hexaklorbensen, Hexaklorsyclohexan, $\alpha$, Hexaklorsyclohexan, $\beta$, Hexaklorsyclohexan, $\delta$, Metamidofos, Monokrotofos, parathion, Metylparation, Propethamphos, toxaphene.

\section{Flame retardants}

There should be no chemical flame retardants in the procured garments, except where this is absolutely necessary due to the function of the textiles. If flame retardancy is required, it will be stated in the tender. In such cases phosphorus and / or nitrogen-based organic compounds, or flame retardants with equivalent or better health and environmental characteristics of flame resistant fabrics must be used. Halogenated flame retardants must not be used under any circumstances.

\section{Alkylphenol ethoxylates}

There should not exist alkylphenoletoxyates in the product. (Nonylphenol is restricted by REACH Annex XVII and priority list, but may nevertheless occur in products). 


\section{MINIMUM QUALITY CRITERIA}

\section{Dimensional changes during washing and drying}

Dimensional changes after washing

and drying shall not exceed:

$+/-3 \%$ for woven products in cotton and cotton mix.

$+/-2 \%$ for the nonwoven products of mixed wool and synthetic fibers.

$+/-4 \%$ for knitwear.

$+/-6 \%$ for coarse knitwear (chunky knit).

+/- 5\% for knitwear (Interlock).

$+/-7 \%$ terry towels and fine rib products.

The requirement does not apply to fibres or yarns, products clearly labeled "dry clean only" or equivalent. The tests shall be conducted in accordance with EN ISO 6330, ISO 5077 or equivalent. The following procedure shall be followed for testing: Wash three times at the temperature indicated on the product, with subsequent drying in a tumbledryer unless another drying process is indicated on the product.

\section{Colour fastness when washing (wash fastness)}

Wash fastness shall be at least level 3-4 for colour change and at least level 3-4 for colour transmission. The requirement does not apply to products clearly labeled "dry clean only" or equivalent, to white products or products that are neither dyed nor printed. The tests shall be conducted in accordance with EN ISO 105-CO6 or equivalent. This means a single washing at the temperature indicated on the product.

\section{Resistance to wet rubbing}

The resistance to wet rubbing shall be at least level 2-3. The requirement does not apply to white products or products that are neither dyed nor printed. The test shall be conducted in accordance with ISO $105 \times 12$ or equivalent.

\section{Resistance to dry rubbing, dry}

Colour fastness to dry rubbing shall be at least level 4. The requirement does not apply to white products or products that are neither dyed nor printed. The test shall be conducted in accordance with EN ISO 105 X12 or equivalent.

\section{AWARD CRITERIA}

\section{Organic cotton or other natural fibres}

Supplementary points will be awarded according to the share by weight of cotton or other natural fibre products that are organically grown. To be considered organic fibres must be cultivated in accordance with Council Regulation (EC) 834/2007 of 28. juni 2007 on organic production and labeling of organic products and repealing Regulation (EEC)

No. 2092 / 91. 


\section{A Quick Overview of Ecolabels}

Deciding whether to include an ecolabel in a tender, needs careful thought and knowledge of what each ecolabel addresses. You should choose an ecolabel to match your environmental ambitions but be careful not to restrict the pool of potential suppliers too much. It may also be that none of the ecolabels address all relevant environmental concerns, and you may want to include additional criteria.

Since 2014 it is now legally acceptable in the EU to specify ecolabels directly within a tender as a criteria, but only ecolabels that meet certain reporting and assurance requirements (see section 3.5.1 in the Buying Green! handbook). This new rule makes it easier for procurers to set environmental criteria and for suppliers to verify that they meet them. In Denmark, however, procurers must allow for suppliers, whose products could meet the criteria but haven't actually received an ecolabel award. Suppliers must provide documentation for this that can be read within an hour! This puts some additional burden on the procurer.

There are many labels for textile products, but only the Nordic Swan has created criteria for textile services. Relevant ecolabels for healthcare textile products include the Nordic Swan, the EU Ecolabel (sometimes called the EU Flower), GOTS (Global Organic Textile Standard) and the Swedish Bra Miljöval (Good Environmental Choice). Though not strictly an ecolabel, the Oeko-Tex $\mathbf{1 0 0}$ label is also sometimes specified in green procurement criteria. The BlueSign label is still only really used for outdoor products and, therefore, not yet relevant to hospital procurers with the possible exception of outdoor work wear.

Be aware that not all ecolabels comply with the criteria set by the EU-Commission in the Buying Green! handbook that allows them to be used in procurement tenders.

The table on page 23 gives a rapid comparison of the environmental issues tackled by the most relevant labels. Two ticks suggest a more stringent and/or comprehensive criteria than a single tick.

A comparison of the same labels with respect to particular chemicals and substances restrictions has also been developed by the Swedish Public Procurement Agency and can be found here.

The aim of the Oeko-Tex label is to protect users of textiles from hazardous chemical residues in clothing and textiles that are put on sale. Restrictions in chemicals under the other ecolabels apply to the whole lifecycle and aim to reduce impacts on ecosystems and people along the whole value chain, including the end user. Oeko-Tex has launched a label (STeP) which covers environmental aspects of production, but this is an environmental management type label for production sites, rather than a product label. It, therefore, has limited relevance to procurers.

The Nordic Swan also has a label and criteria for textile services. The label includes special criteria for laundry of hospital textiles to take account of hygiene standards. The criteria tackle energy use, water use, and detergents/chemicals, in laundries and packaging and transport use in logistics. The label also includes requirements for a minimum share of eco-labelled textiles in the textiles leased out by the textile service.

As a procurer you may wish to consider additional criteria. These can also be inspired by the criteria found in ecolabels. For example, a textile service supplier can receive a Nordic Swan certificate if he meets the minimum criteria and in addition scores 15 points out of a possible 65 award points in the 
Quick comparison between labels for textile products

\begin{tabular}{|c|c|c|c|c|c|}
\hline & Nordic Swan & $\begin{array}{l}\text { EU } \\
\text { Ecolabel }\end{array}$ & Bra Miljöval & $\begin{array}{l}\text { GOTS (natural } \\
\text { fibres only) }\end{array}$ & $\begin{array}{l}\text { Oeko-tex } \\
100\end{array}$ \\
\hline $\begin{array}{l}\text { Share organic } \\
\text { (natural fibres) }\end{array}$ & $\checkmark$ & $\checkmark$ & $\checkmark \checkmark$ & $\checkmark \checkmark$ & \\
\hline $\begin{array}{l}\text { Recycled } \\
\text { content }\end{array}$ & $\checkmark$ & $\checkmark$ & $\checkmark$ & & \\
\hline $\begin{array}{l}\text { Chemical } \\
\text { restrictions in } \\
\text { production } \\
\text { processes }\end{array}$ & $\checkmark \checkmark$ & $\checkmark \checkmark$ & $\checkmark \checkmark$ & $\checkmark \checkmark$ & \\
\hline $\begin{array}{l}\text { Restrictions on } \\
\text { residual } \\
\text { chemicals in } \\
\text { product }\end{array}$ & $\checkmark \checkmark$ & $\checkmark \checkmark$ & & $\checkmark \checkmark$ & $\checkmark \checkmark$ \\
\hline $\begin{array}{l}\text { Water effluent } \\
\text { management }\end{array}$ & $\checkmark \checkmark$ & $\checkmark \checkmark$ & $\checkmark \checkmark$ & $\checkmark \checkmark$ & \\
\hline $\begin{array}{l}\text { Reduced air } \\
\text { pollution }\end{array}$ & & $\checkmark$ & $\checkmark \checkmark$ & & \\
\hline $\begin{array}{l}\text { Reduced solid } \\
\text { waste }\end{array}$ & & & $\checkmark$ & $\checkmark$ & \\
\hline $\begin{array}{l}\text { Product quality } \\
\text { and durability }\end{array}$ & $\checkmark$ & $\checkmark$ & & $\checkmark$ & \\
\hline $\begin{array}{l}\text { Packaging } \\
\text { materials }\end{array}$ & $\checkmark$ & & $\checkmark \checkmark$ & $\checkmark \checkmark$ & \\
\hline $\begin{array}{l}\text { Labour rights/ } \\
\text { working } \\
\text { conditions }\end{array}$ & $\checkmark \checkmark$ & $\checkmark \checkmark$ & $\checkmark \checkmark$ & & \\
\hline $\begin{array}{l}\text { Certification } \\
\checkmark \checkmark 3^{\text {rd }} \text { party } \\
\checkmark 2^{\text {nd }} \text { party }\end{array}$ & $\checkmark \checkmark$ & $\checkmark \checkmark$ & $\checkmark \checkmark$ & $\checkmark \checkmark$ & $\checkmark \checkmark$ \\
\hline
\end{tabular}

Source: Comparison made by Planmiljø

optional criteria. A more ambitious procurer could choose to set a higher threshold of say 25 points against the optional criteria which service providers have to meet.

Finally, before using ecolabels in a tender for a specific product make sure that there are at least two to three suppliers that can meet this. Otherwise you could end up paying a non-competitive price. Most ecolabels have a list over products that have been certified within various categories. It will also help to engage in market dialogue (see Section 2,

pages 10-12).
The criteria for the various ecolabels can be found here:

- Nordic Swan textiles.

- Nordic Swan textiles services.

- EU Ecolabel textiles.

- Bra Miljöval.

- GOTS.

- Oeko-tex 100. 


\section{Section 5}

\section{Choosing your Fibre}

Choosing the right fibre can give significant environmental benefits in all sorts of ways. For example, choice of fibre can affect laundry energy use, durability and environmental impacts of production. They are also important for comfort and hygiene.

When you choose the fibre for your textiles, it is important to consider the properties and the related environmental impact. For example:

\section{- Different fibres have different environmental} profiles during production: the diagram on page 27 has been developed using life cycle assessment (LCA) approaches. Cotton and polyester tend to have greater production impacts than some emerging fibres. Toxicity effects aren't included in the diagram and these would place cotton in a somewhat worse light due to the high use of pesticides in conventional cotton farming. These can be reduced by using organic cotton.

- Some fibres are more durable than others: polyester or a polyester/cotton mix can survive more laundry cycles than $100 \%$ cotton. ${ }^{3}$ Adding an easy care finish can also increase lifetimes.

- Synthetic fibres are easier to launder: since they absorb less water, they use much less energy during tumble-drying. New studies also show that they can be washed at lower temperatures than cotton without compromising hygiene, though this is not recognised in current national hygiene standards.

- Pure fibres and synthetics are easier to recycle after use: $100 \%$ polyester can in theory be recycled back into new textiles again and again and again. 100\% cotton can also be recycled for use in new textiles but it has to be mixed with $80 \%$ of virgin cotton to uphold textile quality. It is more difficult to recycle fibre mixes such as polyester/cotton. Of key importance: any hospital textile recycling strategy should be careful not to compromise durability. A longer lifetime gives far greater environmental benefits than recycling.

- Synthetic fibres can lead to marine microplastic pollution although this is a much smaller source than e.g. car tyres. It is expected that this issue can be tackled in the future through the development of special wastewater filters in laundries. ${ }^{4}$

\footnotetext{
${ }^{3}$ http://www.howstuffcompares.com/doc/c/cotton-vs-polyester.htm

${ }^{4}$ http://www.plasticsouplab.org/showcases/washing-machine-filter/
} 


\begin{tabular}{|c|c|c|c|c|c|}
\hline & Energy use & Water use & $\begin{array}{l}\text { Greenhouse } \\
\text { gasses }\end{array}$ & Waste water & $\begin{array}{l}\text { Direct land } \\
\text { use }\end{array}$ \\
\hline $\begin{array}{l}\text { Decreasing } \\
\text { environment al } \\
\text { impact }\end{array}$ & $\begin{array}{l}\text { Acrylic } \\
\text { Nylon } \\
\text { Polyester/ } \\
\text { PTT } \\
\text { Regen. } \\
\text { cellulosic } \\
\text { (viscose, } \\
\text { Modal) } \\
\text { PLA/ } \\
\text { Cotton/ } \\
\text { Lyocell } \\
\text { Wool } \\
\text { Natural } \\
\text { bast fibres } \\
\text { (nettle, } \\
\text { hemp, flax) }\end{array}$ & $\begin{array}{l}\text { Cotton } \\
\text { Silk } \\
\text { Nylon } \\
\text { Regen. } \\
\text { cellulosic } \\
\text { Acryl } \\
\text { Hemp } \\
\text { Wool } \\
\text { Natural bast } \\
\text { fibres } \\
\text { Polyester }\end{array}$ & $\begin{array}{l}\text { Nylon } \\
\text { Polyester } \\
\text { Lyocell } \\
\text { PLA } \\
\text { Viscose } \\
\text { Modal } \\
\text { Cotton } \\
\text { Natural bast } \\
\text { fibres } \\
\text { Wool }\end{array}$ & $\begin{array}{l}\text { Wool } \\
\text { Regen. } \\
\text { cellulosic } \\
\text { Natural bast } \\
\text { fibres } \\
\text { Nylon } \\
\text { Polyester }\end{array}$ & $\begin{array}{l}\text { Wool } \\
\text { Ramie } \\
\text { Cotton } \\
\text { Flax } \\
\text { Hemp } \\
\text { Viscose } \\
\text { and Modal } \\
\text { Jute } \\
\text { PLA } \\
\text { Lyocell }\end{array}$ \\
\hline
\end{tabular}

Source: EU Technical Background Report to GPP criteria for textiles 2011.

The fibre used also needs to meet other requirements, not least hygiene standards (for example infection control for operation room textiles see Section 6, pages 28-29) and user comfort.

\section{Comfort: is cotton really best?}

Despite its environmental disadvantages, cotton may be the preferred fibre in terms of comfort for hospital staff and patients. This may, however, be based on preconceptions rather than actual experience.

Laboratory tests of comfort exist using standard testing techniques to measure:

- Thermal resistance

- Water vapour resistance
- Air permeability.

- Surface friction and roughness (Kawabata Evaluation System).

- Moisture management (AATCC standard).

- Tensile strength.

However, to break down pre-conceptions it may be worth carrying out staff and patient user-testing of available textile options before making a final choice. User testing may result in findings that alternative fibres give more than acceptable comfort to staff, while giving environmental and economic advantages. ${ }^{5}$ See the box on page 26 for an example of a pilot project that gave exactly this result.

${ }^{5}$ http://www.greenercleaner.net/natural-or-synthetic-textiles/ 


\section{INNOVATIVE PROCUREMENT OF UNIFORMS AT RAWICZ HOSPITAL}

In 2011, Rawicz County Hospital in Poland engaged in the LCB-Healthcare Network an EU funded network for innovative procurement. A pilot innovation procurement project was launched at the hospital focussing on more sustainable procurement of staff uniforms.

The pilot project began by consulting nurses, doctors and other staff on the key functional parameters required for uniforms. This proved to be an empowering experience for staff, which resulted in the following priorities: the new uniforms had to be functional, attractive, user friendly, easy to clean, durable and cost-effective.

Specifying these functional outcomes in tender documents, rather than specifying material, fibre type, design and so on, gave procurers and suppliers the opportunity to examine more innovative solutions. Moreover, after having gained interest from a further eight hospitals in Poland in the pilot project results, it was possible to attract a wide range of suppliers to develop offers.

The hospital pro-actively communicated its needs and market requirements and an open meeting was held with potential suppliers. Feedback was very positive and the open specification gave suppliers an opportunity to differentiate their products on factors other than purchase price. In particular total costs of ownership (TCO - see Section 7, pages 30-31) was given precedence over initial purchase costs when evaluating offers from suppliers.

The result of the market dialogue and tendering process were uniforms produced from a mixture of polyester and tencel (a Eucalyptus based product). The material blend was found to be as resilient during the washing process, quicker to dry, less prone to staining and received general approval for quality and functionality. Although initial purchase price was higher than some competing bids, it had the cheapest total costs of ownership, due to reduced laundering costs and longer lifetimes.

For more information please contact Marcin Kautsch e-mail: mxkautsc@wp.pl 


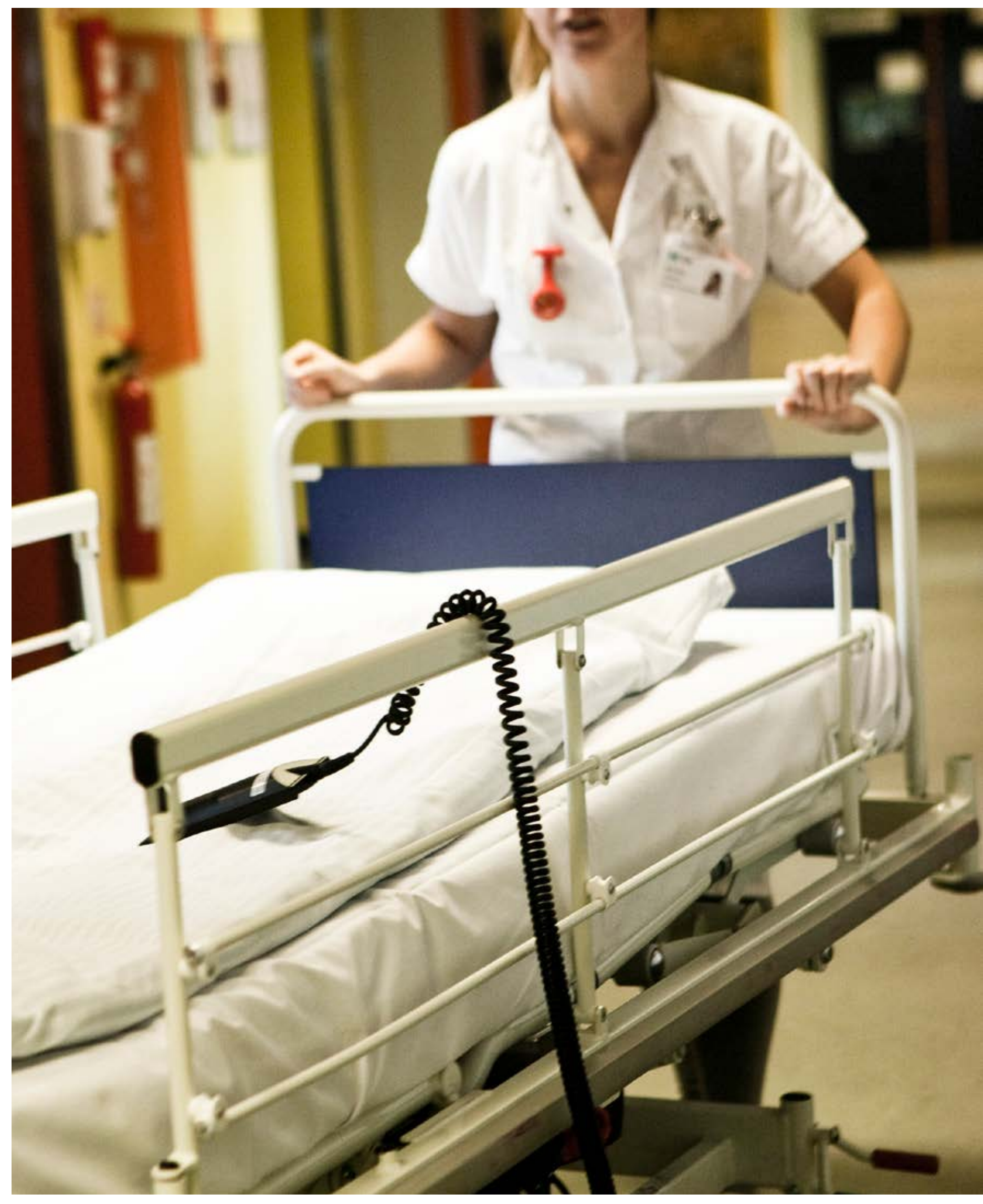




\section{Section 6}

\section{Single Use versus Reusable Textiles}

There are pros and cons to both disposable non-wovens and reusable textile products.

This is particularly the case for operation room textiles where infection control is of paramount importance. In addition to hygiene, other important variables are total cost per use, functionality and comfort and, of most relevance here, environmental considerations.

Single use and modern reusable operation room textiles are more or less equivalent with respect to barrier protection, which is a critical element of infection control. This is dependent on reusable textiles being laundered and sterilised following approved procedures after each use.

Minimising release of airborne particles is also of importance to infection control. Modern reusable barrier fabrics produced from continuous filaments have much lower potential for releasing lint than traditional cotton fabrics, and perform as well as single use non-woven products. They also perform well in comfort and breathability.

Study results are mixed with respect to cost per use of single use versus reusable and the comparison will be very country specific. Higher labour costs may favour single use, while high waste disposal costs will favour reusable.
On the other hand several studies find that reusable textiles give significant environmental benefits compared to single use textiles. ${ }^{6,7,8,9}$

A review of six lifecycle assessments found that disposable textiles have 2 to 3 times the carbon footprint, energy use and water use, per use in the operation room than modern reusables. ${ }^{10}$

Since modern reusable textiles are better or comparable in other respects to single use, they seem to be the more sustainable choice.

Using reusable operation room (OR) textiles is dependent on the hospital having the capacity to sterilise reusable surgical packs.

The following advice can be given to hospitals and their laundry services that wish to convert from single use to reusable OR textiles: ${ }^{11}$

\footnotetext{
${ }^{6}$ Overcash (2012) A Comparison of Reusable and Disposable Perioperative Textiles: Sustainability State-of-the-Art 2012 http://www.ncbi.nlm.nih.gov/pubmed/22492184

${ }^{7}$ Carre (2008) LCA Comparing Laundered Surgical Gowns with Polypropylene Based Disposable Gowns http://trlaa.com.au/wordpress/wp-content/uploads/Lifecycle_Assessment_Study.pdf

${ }^{8}$ Mikusinska (2012) Comparative Life Cycle Assessment of Surgical Scrub Suits

http://kth.diva-portal.org/smash/get/diva2:574013/FULLTEXT01.pdf

${ }^{9}$ Erikkson and Berg (2003) Livscykelanalys av Operationsrockar

http://www.vgregion.se/upload/Tv\%C3\%A4tteriet\%20Alings\%C3\%A5s/LCA\%2Ooperationsrockar_granskad.pdf

${ }^{10}$ Overcash (2012) A Comparison of Reusable and Disposable Perioperative Textiles: Sustainability State-of-the-Art 2012

http://www.ncbi.nlm.nih.gov/pubmed/22492184

${ }^{11}$ https://americanlaundrynews.com/articles/winning-sale-reusable-surgical-textiles-part-1
} 


\begin{tabular}{|l|c|c|c|}
\hline & Cotton reusable & Disposables & High tech reusable \\
\hline Barrier effect & - & + & + \\
\hline Cleanliness & + & - & + \\
\hline Particle emission & - & - & + \\
\hline $\begin{array}{l}\text { Comfort and } \\
\text { breathability }\end{array}$ & + & - & + \\
\hline Environmental impact & $+/-$ & + & + \\
\hline Functionality & - & $+/-$ & $+/-$ \\
\hline Cost effective & $+/-$ & $+/-$ & + \\
\hline Value for money & - & & + \\
\hline
\end{tabular}

Source: Petel, M. (2014) $)^{12}$

1. Start small. Begin with a manageable plan, say OR towels and surgical gowns.

2. Work with your reusable OR supplier. Tap the knowledge and resources your supplier can provide. Reach out to other laundries that have successfully converted hospitals to a reusable OR program.

3. Prepare an outline comparing disposable products to reusable alternatives. This comparison should include costs; product and barrier attributes; sterilization; disposal costs; delivery; staffing; and any other services your laundry can provide.

4. Once you have initial buy-in, establish a multidisciplinary team.
5. Offer the team (environmental officers, clinical staff and decision-makers) a tour of the laundry and pack room.

6. Begin a product trial for a few weeks. There may be those against a reusable program, but let them sample it.

7. Set up a clear process for conducting the actual conversion (one that uses up old disposable inventory, etc.).

8. Continue to provide support and education to the staff, as well as evaluate and measure results. 


\section{Section 7}

\section{Using Total Costs of Ownership}

Total costs of ownership (TCO) captures the costs associated with a product over its entire lifetime. Making decisions based on TCO rather than purchase price can give environmental benefits.

When making the choice between textile products often the cheapest product may not be the most environmentally beneficial. However, when the lifecycle costs of a product are calculated there may be a greater compatibility between environmental gains and management of budgets. This will particularly be the case for more durable textiles, which will save both money and environmental resources although they may cost more upfront. The choice between single-use and multiple-use textiles (see Section 6, pages 28-29) can also become clearer after calculating life-cycle costs or the Total cost of ownership (TCO) as it is also referred to.

TCO captures the costs associated with a product over its entire lifetime from purchase to end of life. TCO provides a framework and language for describing and measuring sustainability impacts in a way that procurement managers can readily understand. For example, TCO can be used together with LCA and similar approaches to uncover (and communicate) opportunities for both cost savings and sustainability benefits for things such as energy and water efficiencies.

The use of TCO considerations requires knowledge about the factors that must be included in the calculations, and a good overview of how the product is used. For healthcare textile products this will include knowledge of:

- initial price

- numbers of uses before the product is worn out

- laundering energy water use and associated costs

- need for and cost of repair

- costs of disposal.

You can use TCO to choose between different suppliers of textiles (see Rawicz Hospital case on page 28). Remember to make suppliers document the durability (number of uses before failure) of their textiles, as this is the key factor in a TCO. If possible include a contract clause that holds them to this level.

Most large textile service companies will have developed TCOs to allow them to minimise costs and may make these calculations for you. The same may be true of national procurers such as Sykehusinnkjøp HF in Norway. However, procurers at regional, municipality or hospital level may find it too resource intensive to develop TCO-calculators for all the products they purchase including textiles. 


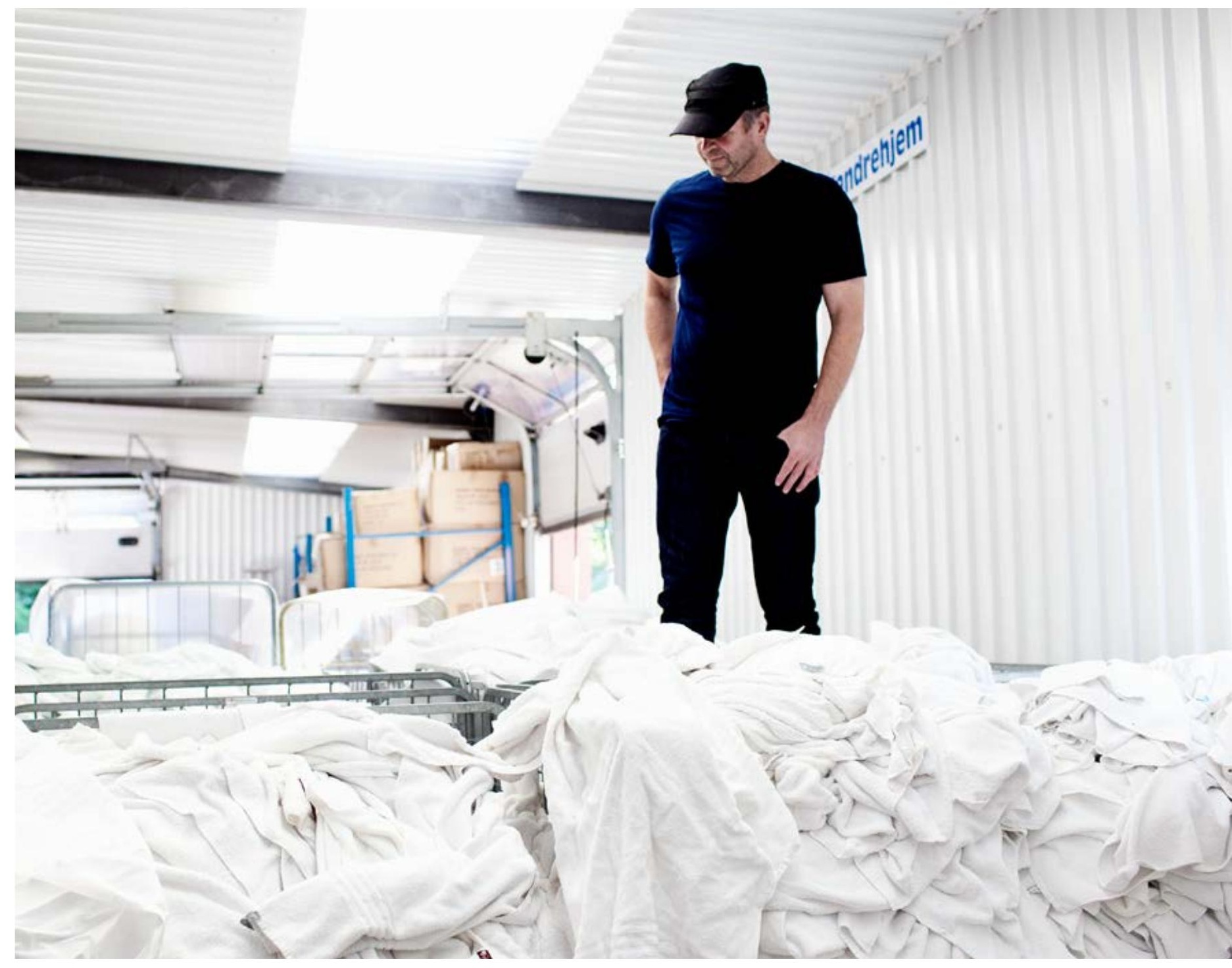

While there are a number of tools and tips to lean on when considering TCO there are, as yet, no publicly available calculators for TCO of textile healthcare products. You can find more generalised info and tools here:

- The Danish Forum on Sustainable Procurement - a national network which is a knowledge sharing forum where procurers from both public and private organisations can keep updated on best practice, methods and tools for green procurement incl. TCO tools (Danish).
- The Responsible Procurer - a webpage where procurers can find green criteria ready to copy paste into tender documents for a number of product areas and Total Cost of Ownership tools for selected product areas (Danish).

- BSR (Business for Social Responsibility) (English). 


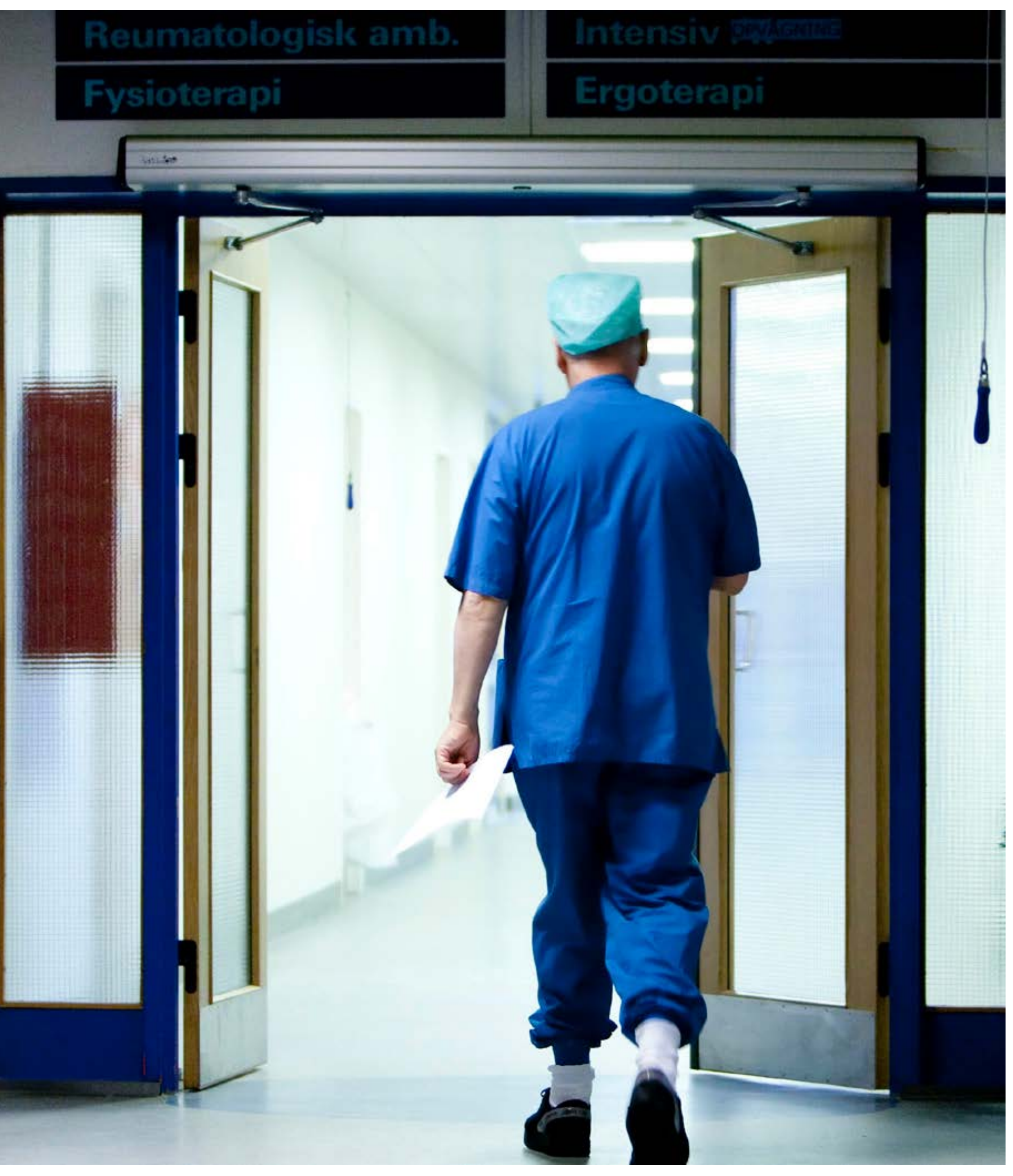




\section{Section 8}

\section{About the Guide and the Network Behind}

This guide has been developed as part of an initiative under the Nordic Action Plan for Sustainable Fashion and Textiles "Well-dressed in a Clean Environment" and is funded by the Nordic Council of Ministers.

The Nordic Action Plan identifies the green public procurement as an important leverage point. Firstly, because the public sector in itself is a significant consumer of textiles - with a value of EUR 10 billion per year at EU level. ${ }^{13}$. Secondly, green public procurement can establish markets and processes, which can have positive knock-on effects and inspire private procurers to follow suit.

The guide has been developed in cooperation with a Nordic Network of Procurers in the Health Sector. The network is initiated by the Danish Environmental Protection Agency on behalf of the Nordic Council of Ministers. PlanMiljø ApS and TEM have assisted in the process, facilitated the network and drafted the guide. The network comprised the following members:

Christian Leth Christensen, Region Central Denmark Anette Bjørn, Region Southern Denmark

Susanne G. Sørensen, Region Northern Jutland,

Denmark

Anya S. Midjord and Gudna á Rógvi Joensen, LSH Hospital, Faroe Islands Isa-Maria Bergman, Motiva, Finland Outi Kalske, Hospital District of Southwest Finland Karólína Guðmundsdóttir, Landspítali Háskólasjúkrahús, Iceland Trude Ertresvåg, Sykehuspartner HF, Norway
Kine Stjern and Evy Pleym, Sykehusinnkjøp HF, Norway Anna Chistiansson, Uphandlings-myntigheten, Sweden Anja Ekstrand and Sofie Areborn, Region Skåne, Sweden Jonna Bjuhr Männer, Koncernkontoret Region Västra Götaland, Sweden Christina Nukala-Pengel, Ålands Hälso- och Sjukvård, Åland Rikke Dreyer and Lena Stenseng, Ecolabel Denmark

Weronika Rehnby, TEKO Malin Hill, Berendsen $A B$ Hanne Selsholt Britz and Søren Vinzent, De Forenede Dampvaskerier A/S

Fredrik Johansen, FOV Fabrics $A B$

Kate Riley, Oakdene Hollins

Marie Pettersson and Daniel Eriksson, TEM

Rikke Fisher-Bogason and David Watson, PlanMiljø Birgitte Jørgensen Kjær and Anne-Mette Lysemose Bendsen, Danish EPA

Questions about the guide and the network can be sent to Birgitte Jørgensen Kjær, Danish Environmental Protection Agency, bjk@mst.dk

\footnotetext{
${ }^{13} \mathrm{http} / / /$ susproc.jrc.ec.europa.eu/textiles/docs/141222\%20EU\%20GPP\%2OTextiles_Technical\%2Obackground\%2Oreport_Draft\%20 version\%201.pdf
} 
Nordic Council of Ministers

Ved Stranden 18

DK-1061 Copenhagen K

www.norden.org

This guide is aimed at procurers in the Nordic healthcare sector who are responsible for purchasing textile products and services and assists them in developing processes for establishing suitable and practicable environmental criteria in tender documents. Procurers can learn which aspects in the production and care of textiles have most environmental significance and how these can be addressed through criteria. They can learn more about the role of ecolabels in procurement and can find links to ready-to-use criteria, and other useful information from national procurement agencies. The guide has been developed in cooperation with a Nordic Network of Procurers in the Health Sector as part of an initiative under the Nordic Action Plan for Sustainable Fashion and Textiles "Well-dressed in a Clean Environment". It is funded by the Nordic Council of Ministers. 